\title{
AÇÕES ADOTADAS PELAS EMPRESAS DA B3 ALINHADAS COM OS 17 OBJETIVOS DE DESENVOLVIMENTO SUSTENTÁVEL (ODS): UMA ANÁLISE DOS RELATÓRIOS DE SUSTENTABILIDADE
} ACTIONS ADOPTED BY B3 COMPANIES ALIGNED WITH
THE 17 SUSTAINABLE DEVELOPMENT GOALS (ODS): AN
ANALYSIS OF SUSTAINABILITY REPORTS

0 artigo foi aprovado e apresentado no $3^{\circ}$ Congresso UFU de Contabilidade, realizado de $17 / 10$ a 18/10 de 2019, em Uberlândia (MG)

\section{RESUMO}

A preocupação com as questões sociais, ambientais e econômicas é uma tendência mundial. Dada essa importância, as empresas podem publicar relatórios de sustentabilidade para evidenciar suas ações socioambientais. Portanto, o objetivo da pesquisa é verificar nos relatórios de sustentabilidade, publicados em 2017 e 2018, as ações adotadas pelas empresas da Brasil, Bolsa, Balcão (B3) para contribuir com os 17 Objetivos de Desenvolvimento Sustentável (ODS). A amostra é constituída por 44 empresas, e as informações foram coletadas por meio da análise de conteúdo dos relatórios de sustentabilidade. A partir desses dados, gerou-se uma análise fatorial com o objetivo de agrupar os ODS em fatores. Dessa forma, formaram-se quatro fatores, denominados de fator Econômico, fator Social, fator Ambiental e fator Preservação. Sendo assim, o estudo apontou, dentro desses grupos, em quais ODS as empresas têm mais ações voltadas para o atingimento do desenvolvimento sustentável. Os resultados mostram que as empresas da B3 empregam esforços em prol dos ODS relacionados à melhoria das comunidades onde estão instaladas e oferecem beneficios aos trabalhadores para garantir sua saúde e bem-estar. Além disso, adotam medidas para reduzir impactos ambientais e preservar a vida na terra e na água. Assim, a principal contribuição da pesquisa é demonstrar que os ODS implementados, bem como as ações para atingi-los, estão relacionados ao âmbito interno das empresas. Diante disso, é necessário um maior esforço para colaboração com o meio externo à empresa, como erradicação da fome e da probreza.

Palavras-chave: Relatórios de sustentabilidade; Desenvolvimento Sustentável; ODS.

\begin{abstract}
Concern with social, environmental and economic issues is a worldwide trend. Given this importance, as companies can publish sustainability reports to highlight their social and environmental actions. Therefore, the objective of the research is to verify the sustainability reports, published in 2017 and 2018, as actions taken by companies in Brazil, Bolsa, Balção (B3) to contribute to the 17 Sustainable Development Goals (SDGs). The sample is selected by 44 companies and the information was collected by analyzing the content of the sustainability reports. From these data, you can analyze a factor analysis with the objective of grouping the SDGs into factors. Thus, they form four factors called economic factor, social factor, environmental factor and preservation factor. Therefore, the study pointed to these groups in which SDGs are companies that have more actions focused on sustainable development. The results show that B3 companies employ the benefits of ODS related to the improvement of communities where they are installed and benefit workers from health and well-being guarantee services. In addition, we have adopted measures to reduce environmental impacts and preserve life on land and in water. Thus, the main contribution of the research is to demonstrate that the SDGs implemented, as well as the actions to achieve the values related to the internal scope of the companies. Therefore, a greater collaborative effort with the external environment is necessary, such as the eradication of hunger and poverty.
\end{abstract}

Keywords: Sustainability reports; Sustainable development; ODS.
Barbara Siqueira da Silva

Mestre em Contabilidade Financeira pela Universidade Federal de Minas Gerais (UFMG) Especialista Contabilidade Pública pela Faculdade de Venda Nova do Imigrante (FAVENI). Graduado em Ciências Contábeis pela Universidade Federal de Minas Gerais (UFMG). Contadora na Prefeitura de Lagoa Santa/MG. Contato: Av. Pres. Antônio Carlos, 6627, FACE, Sala 2035- Pampulha, Belo Horizonte MG, 31270-901.E-mail: barbara.s_silva@hotmail.com

\section{Jamile Neme de Queiroz}

Mestre em Controladoria e Contabilidade pela Universidade Federal de Minas Gerais (UFMG) Especialista em Controladoria e Finanças pelo Instituto Superior de Educação Ateneu. Graduada em Ciências Contábeis pela Universidade Federal de Minas Gerais (UFMG). Coordenadora Tributaria. Contato: Av. Pres. Antônio Carlos, 6627 FACE, Sala 2035- Pampulha, Belo Horizonte - MG, 31270-901. E-Mail: jamile.dequeiroz@gmail.com

\section{José Roberto de Souza Francisco} Professor Efetivo do Departamento de Ciências Contábeis e Controladoria \& Finanças da UFMG e do Programa de Pós-Graduação em Controladoria \& Finanças da UFMG; Doutor em Finanças, CEPEAD/UFMG; Mestrado Profissional em Administração pela FEAD-MINAS Centro de Gestão Empreendedora; Especialização em Gestão do Cooperativismo pela Faculdade de Ciências Humanas de Pedro Leopoldo; Aperfeiçoamento em Controladoria e Finanças pela UFMG; Graduação em Ciências Contábeis pelo Centro Universitário Newton Paiva; Coordenador do Colegiado Pós-graduação em Controladoria e Contabilidade (PPGC/CIC/FACE/IFMG) (março/2021 a atual); Contato: Avenida Presidente Antônio Carlos, 6627 - Prédio FACE-Bairro Pampulha-Belo Horizonte-MG-CEP. 30.270-901 E-mail · jroberto@face ufmg br

\section{Ricardo Carvalho da Silva \\ Doutorando em Controladoria e Contabilidade na Universidade Federal de Minas Gerais (UFMG). Mestre em Controladoria e Contabilidade pela Universidade Federal de Minas Gerais (UFMG). Especialista em Gestão Financeira: Controladoria e Auditoria pela Fundação Getúlio Vargas (FGV), Graduado em Administração pela Universidade Federal de Minas Gerais (UFMG) Graduado em Ciências Contábeis pela Pontifícia Universidade Católica de Minas Gerais (PUC-MG). Professor e Empresário Contábil. Contato: Av. Pres. Antônio Carlos, 6627. FACE Sala 2035- Pampulha, Belo Horizonte - MG, 31270-901. E-mail: rickmaisbh@gmail.com}




\section{INTRODUÇÃO}

O desenvolvimento sustentável "procura satisfazer as necessidades da geração atual, sem comprometer a capacidade das gerações futuras de satisfazerem as suas próprias necessidades” (WCED, 1987, p. 12). Diante disso, em 2015, a Organização das Nações Unidas (ONU) estabeleceu 17 Objetivos de Desenvolvimento Sustententável (ODS), segregados em 169 metas, para serem atingidos até 2030 (ONUBR, 2015). Para Jones, Wynn, Hillier e Comfort (2017), os ODS são um plano ambicioso de desenvolvimento sustentável, visando à integração de empresas, governos e sociedade em busca de preservação das pessoas e do planeta.

A sustentabilidade derivou do conceito de desenvolvimento sustentável e começou a ganhar adeptos nos anos de 1990, quando Elkington (1997) introduziu a noção do triple bottom line (TBL) e o ligou à ideia de sustentabilidade. O TBL consiste em uma estrutura contábil, que incorpora três dimensões de desempenho: social, ambiental e financeiro. Assim, o TBL vai além dos relatórios contábeis tradicionais, uma vez que inclui dados ambientais e medidas sociais. Dessa forma, captura a essência da sustentabilidade, medindo o impacto das atividades de uma organização no mundo incluindo rentabilidade, valor para os acionistas e seu capital social, humano e ambiental (Elkington, 1997).

Para atingir os seus objetivos, os relatórios de sustentabilidade mensuram e divulgam os impactos socioambientais decorrentes das atividades cotidianas das empresas (Reverte, 2009). Entre os benefícios da adesão e divulgação destes relatórios, citam-se a maior transparência e atendimento das demandas informacionais de responsabilidade social e ambiental dos stakeholders (Bassetto, 2010). O caráter voluntário do relatório de sustentabilidade, no Brasil, oferece às organizações a possibilidade de elaborar o seu próprio relatório ou aderir a modelos desenvolvidos pela Global Reporting Iniciative (GRI), pelo Instituto Ethos ou pelo Instituto Brasileiro de Análises Sociais e Econômicas (IBASE) (Campos et al., 2013).

Considerando a possibilidade da publicação voluntária, emerge a necessidade da análise da Teoria da Divulgação Voluntária, que, entre outras possibilidades, destaca que os dados ambientais são passíveis de discricionariedade. Portanto, as empresas buscarão comunicar desempenhos positivos e omitir informações desfavoráveis, para, assim, não causarem prejuízos à empresa, devido à má interpretação dos stakeholders (Dye, 2001). As entidades também levam em consideração os custos e os benefícios antes de elaborar e publicar as informações (Verrecchia, 2001).

Diante do contexto da crescente preocupação com as questões atreladas à expansão econômica sustentável e da importância dos relatórios de sustentabilidade, formulou-se a seguinte questão de pesquisa: quais ações as empresas listadas na B3 têm adotado para contribuírem com os 17 objetivos de desenvolvimento sustentável? $O$ objetivo da pesquisa é verificar, nos relatórios de sustentabilidade, publicados em 2017 e 2018, as ações adotadas pelas empresas da B3 para contribuir com os 17 Objetivos de Desenvolvimento Sustentável (ODS)

As empresas devem saber avaliar a sua contribuição e estratégias para que os 17 ODS sejam atingidos. Porém, para alcançar os objetivos desejados, adequar-se aos desafios da implementação de medidas para contribuir com a sustentabilidade e divulgar para a sociedade o impacto de suas ações, as companhias deverão saber o que e como reportar as informações nos relatórios contábeis (PWC, 2017).

Diante do exposto, a pesquisa justifica-se pelo papel de destaque das empresas dentro da sociedade, não apenas gerando renda, mas também consumindo recursos e causando impactos positivos ou não, tanto na economia quanto no aspecto social e ambiental. Uma forma de mostrar as contribuições e ações voltadas para a sociedade é por meio dos relatórios de sustentabilidade. Dessa forma, uma análise desses documentos permite avaliar as principais medidas adotadas pelas entidades, como estão sendo reportadas e se, de fato, estão levando em consideração os objetivos da Agenda 2030.

\section{REFERENCIAL TEÓRICO}

\subsection{Teoria da Divulgação Voluntária}

De acordo com Yamamoto e Salotti (2006), evidenciação é a informação contábil, qualitativa ou quantitativa, divulgada pelas empresas com o objetivo de auxiliar os usuários nas tomadas de decisões e nas percepções sobre os riscos e oportunidades que a empresa oferece. Iudícibus (2010) destaca que a transparência é um compromisso inalienável da contabilidade para os seus usuários e com os seus objetivos.

Para Gonçalves e Ott (2002, p. 3), a divulgação vai além das demonstrações contábeis e abrange as informações relevantes de cunho voluntário que podem ser disseminadas por meio de Relatório da Administração, Atas de reuniões com analistas de mercado/acionistas, relatórios de sustentabilidade, entre outros. A evidenciação de informações contábeis é abordada principalmente pela Teoria da Divulgação, cujo objetivo é explicar fenômenos relacionados à divulgação com base em evidências empíricas e modelos de análises provenientes das teorias econômicas (Rover, Tomazzia, Murcia \& Borba, 2012).

Verrecchia (2001) identifica três categorias de pesquisa sobre os processos da divulgação de informações na contabilidade: divulgação baseada em associação, divulgação baseada em eficiência e divulgação baseada em julgamento, uma vez que acredita não existir uma única teoria abrangente o suficiente. A divulgação baseada em associação relaciona os fenômenos contábeis e seus reflexos para investidores e mercados de capitais. Já a divulgação baseada em eficiência engloba informações que reduzem o custo de capital, ou seja, possui uma vertente econômica. A divulgação 
baseada em julgamento compreende as informações obrigatórias, porém, leva em consideração que os gestores podem gerenciar informações de caráter voluntário, dando delineamento à Teoria da Divulgação Voluntária (Verrecchia, 2001).

Em contraste com Verrechia (2001), que afirma a existência de mais de uma teoria que explica a evidenciação da informação pelas empresas, Dye (2001) defende que as organizações publicam apenas aquelas informações que são favoráveis a elas, omitindo as informações que não são bem vistas pelo mercado. Assim, conforme assegura o autor, apenas a Teoria da Divulgação Voluntária é suficiente para explicar as divulgações das informações pelas entidades.

Desta forma, Dye (2001) argumenta que a divulgação é impulsionada pela possibilidade de escolha do agente. Para o autor, os relatórios anuais buscam trazer credibilidade para a empresa, assim tendem a destacar os sucessos obtidos em detrimento dos resultados desfavoráveis. Além disso, a Teoria da Divulgação Voluntária relata que os investidores possuem expectativas racionais e o silêncio diante da divulgação de uma informação indica que esta não é benéfica para a reputação da empresa (Verrecchia, 2001; Dye, 2001).

Nesta mesma linha de pesquisa, Clarkson et al. (2008) indicam que as empresas que não têm um padrão de divulgação ambiental bem desenvolvido tendem a divulgar menos ou serem omissas. Assim, para os autores, pode-se atribuir uma relação positiva entre o desempenho ambiental e a divulgação ambiental, como evidência para a aplicação da teoria do disclosure voluntário.

\subsection{Sustentabilidade}

A preocupação com um desenvolvimento mais sustentável intensificou-se a partir do início da década de 1970, no continente europeu. O temor era de que o desenvolvimento colocasse em risco a sustentabilidade do planeta (Meadows, Meadows, Randers \& Behrens, 1972). A década de 1980 foi marcada por grandes descobertas científicas, tais como o efeito estufa e o afinamento da camada de ozônio (Campos et al., 2013).

Em 1992, a Conferência das Nações Unidas sobre Meio Ambiente e Desenvolvimento (RIO-92) trouxe uma visão mais ampla de desenvolvimento sustentável, baseando-o em três pilares - econômico, social e ambiental (Lago, 2007). Esses pilares foram denominados de triple bottom line (TBL) por Elkington (1997). Os fatores econômicos estão relacionados à economia formal e à informal, que geram atividades para os indivíduos obterem renda e melhorarem os padrões de vida (Almeida, 2009). O pilar ambiental refere-se ao impacto das atividades no meio ambiente, bem como a utilização de recursos naturais. E por fim, a dimensão social está ligada ao ser humano e à sociedade, abrangendo tanto o âmbito interno das empresas quanto o externo (Almeida, 2009).

A sustentabilidade e o crescimento econômico geram um impasse, pois, de um lado, estão os otimistas, como Garcia (2016) que aponta um caminho baseado na limitação do crescimento em prol de favorecer um ambiente sustentável. Para o autor, é possível haver uma combinação ótima entre conservação e crescimento econômico. Por outro lado, há aqueles que defendem que a sustentabilidade ambiental só é possível se não houver nenhum crescimento econômico (Oliveira, 2012).

Para Pronk e ulHaq (1992) e Bossel (1999), os sistemas sociais, ambientais e econômicos estão interligados e contidos um dentro do outro. Segundo Pronk e ulHaq (1992, p. 30), “o desenvolvimento é sustentável quando o crescimento econômico traz justiça e oportunidades para todos os seres do planeta, sem privilégio de algumas espécies, sem destruir os recursos naturais finitos e sem ultrapassar a capacidade de carga do sistema”.

Desse modo, sustentabilidade econômica refere-se à alocação e distribuição dos recursos naturais de forma eficiente. Já sustentabilidade social é o desenvolvimento com crescimento estável e distribuição igualitária de renda, gerando uma redução das diferenças sociais (Bellen, 2005). Na perspectiva ambiental, sustentabilidade tem como principal preocupação os impactos da atividade humana sobre o ambiente (Bellen, 2005).

Para Romeiro (2012), o desenvolvimento sustentável deveria ser entendido como um processo de melhoria do bem-estar humano. A produção material e energética deve garantir o conforto e ser estabilizada em um nível compatível com os limites termodinâmicos do planeta. Por conseguinte, o Estado deve ser estacionário, no qual o crescimento do consumo como fator de emulação social cede lugar ao crescimento cultural, psicológico e espiritual (Romeiro, 2012).

Diante desse cenário em que o desenvolvimento sustentável ganha força, o relatório de sustentabilidade é o documento utilizado no âmbito empresarial para divulgar suas ações, impactos e atividades realizadas que contribuem com o desenvolvimento sustentável (Campos et al., 2013). A divulgação dos relatórios dá-se de forma voluntária, e não há uma normatização que resulte em uma padronização dos relatórios socioambientais.

Neste aspecto, inserem-se organizações, como a Global Reporting Initiative (GRI), com objetivo de desenvolver diretrizes globais para elaboração de relatórios de sustentabilidade, permitindo a comparabilidade entre as organizações de todo o mundo (Leite, Prates \& Guimarães, 2009). O modelo de relatório evidencia um conjunto de indicadores relativos ao desempenho econômico, social e ambiental, organizado de forma que reduza as informações desconexas e irrelevantes, e, assim, produza resultados mais claros e objetivos (Basseto, 2010).

Para Costa e Marion (2007), existe uma dificuldade em analisar informações ambientais, uma vez que há pouca uniformidade na estrutura dos relatórios disponibilizados pelas empresas. Ribeiro, Bellen e Carvalho (2011) destacam que os níveis de evidenciação ambiental das companhias reagem aos estímulos regulatórios de seus países. Calixto (2013), avaliando a adesão à prática de evidenciação de sustentabilidade, baseado no relatório GRI, por empresas situadas na América Latina, demonstrou que as empresas brasileiras foram as que mais destacaram as informações socioambientais 
em seus relatórios. Verificou-se ainda que o relatório anual é o principal canal utilizado pelas companhias para ressaltar tais informações socioambientais, seguido do relatório de sustentabilidade, divulgado como parte do relatório anual ou como uma publicação específica.

Em 2015, os Estados-Membros da ONU estabeleceram um acordo histórico sobre a agenda para o desenvolvimento sustentável mundial, a Agenda 2030, cujo plano de ação é focado nos " 5 Ps": pessoas, paz, planeta, prosperidade e parceria (Halle \& Wolfe, 2016). A Agenda destina-se a promover o bem-estar social, a prosperidade, a paz e a justiça em um planeta saudável e ambientes sustentáveis, com base no respeito aos direitos humanos e à igualdade de gênero (Andrade, 2017).

Além dos 17 ODS, a Agenda 2030 destaca a importância de as empresas adotarem práticas sustentáveis e divulgarem essas ações, em relatórios de sustentabilidade. Singh et al. (2018) enfatizam que entender e estabelecer metas de desenvolvimento sustentável pode auxiliar na priorização e na escolha de políticas ambientais, sociais e econômicas de forma eficiente. Deste modo, é válido que as empresas divulguem suas ações, impactos e medidas socioambientais, que estão sendo adotadas para auxiliar no monitoramento e contribuir com a tomada de decisões (Reverte, 2009; Bassetto, 2010).

A PWC, em 2017, realizou um estudo para verificar se as empresas compreendem o que o cumprimento dos ODS exige e o papel que devem desempenhar para ajudar a alcançá-los. Para isso, analisou os relatórios de sustentabilidade de 470 empresas no mundo todo. A análise tinha o objetivo de verificar quais ODS as empresas estavam priorizando, o porquê e como estavam reportando estes objetivos. Os resultados indicaram que $62 \%$ das empresas analisadas referiram-se aos ODS em seus relatórios. Contudo, destes $62 \%$, apenas $37 \%$ têm priorizado os ODS individualmente, e $25 \%$ referem-se aos objetivos sustentáveis de forma geral. As empresas restantes, ou seja, 38\%, não abordam os objetivos em seus relatórios.

Para Schio, Mazzioni, Moura e Dal Magro (2019), as empresas do mercado brasilerio possuem características que podem determinar a evidenciação dos ODS nos relatórios de sustentabilidade. Para os autores, as empresas maiores, as integrantes do ISE, as com vendas para o exterior e as com menor concentração acionária estão mais propensas a divulgar informações referentes aos ODS.

\section{PROCEDIMENTOS METODOLÓGICOS}

\subsection{Tipologia da Pesquisa, Definição da Amostra e Coleta de Dados}

A pesquisa é descritiva quanto aos objetivos e documental quanto aos procedimentos, pois oferece tratamento análitico e descritivo aos relatórios de sustentabilidade. Em relação à abordagem do problema, o estudo é quantitativo e qualitativo, pois emprega análise de conteúdo para coletar os dados e oferece tratamento estatístico para consecução do objetivo de pesquisa (Martins \& Theóphilo, 2009).

Os relatórios de sustentabilidade são adotados de forma voluntária pelas empresas brasileiras. Contudo, como forma de incentivar sua elaboração e publicação, a B3 criou, em dezembro de 2011, o "Relate ou Explique", no qual as empresas declaravam se possuíam o relatório de sustentabilidade ou não e o porquê. Essa medida teve duração até 2015 , quando a CVM destinou um campo exclusivo no formulário de referência para essa informação. O Objetivo do "Relate ou Explique" é estimular a publicação de informações ambientais, sociais e de governança. A partir de 2017, a B3 lançou o "Relate ou Explique para os Objetivos de Desenvolvimento Sustentável (ODS)". O objetivo agora é verificar se as empresas estão levando em consideração esses objetivos na elaboração de seus relatórios de sustentabilidade

As iniciativas da B3 produziram resultados positivos. Em 2012, no primeiro ano do "Relate ou Explique", 45,31\% das empresas publicaram ou explicaram o motivo de possuírem ou não relatórios de sustentabilidade; em 2013, este número subiu para $66,29 \%$, em 2014 , para $71,17 \%$; e, em 2015 , para $71,65 \%$. O número de empresas que publicam o relatório passou de 96, em 2012, para 160, em 2015, ou seja, houve um crescimento de aproximadamente 60\% (B3, 2018).

Diante do exposto, a amostra foi constituída por 44 empresas que declararam, no "Relate ou Explique" da B3, levar em consideração os 17 ODS na elaboração dos relatórios de sustentabilidade, nos anos de 2017 e 2018 . A Figura 1 demonstra por setor as empresas que compõem a amostra. 
Figura 1 - Empresas componentes da amostra

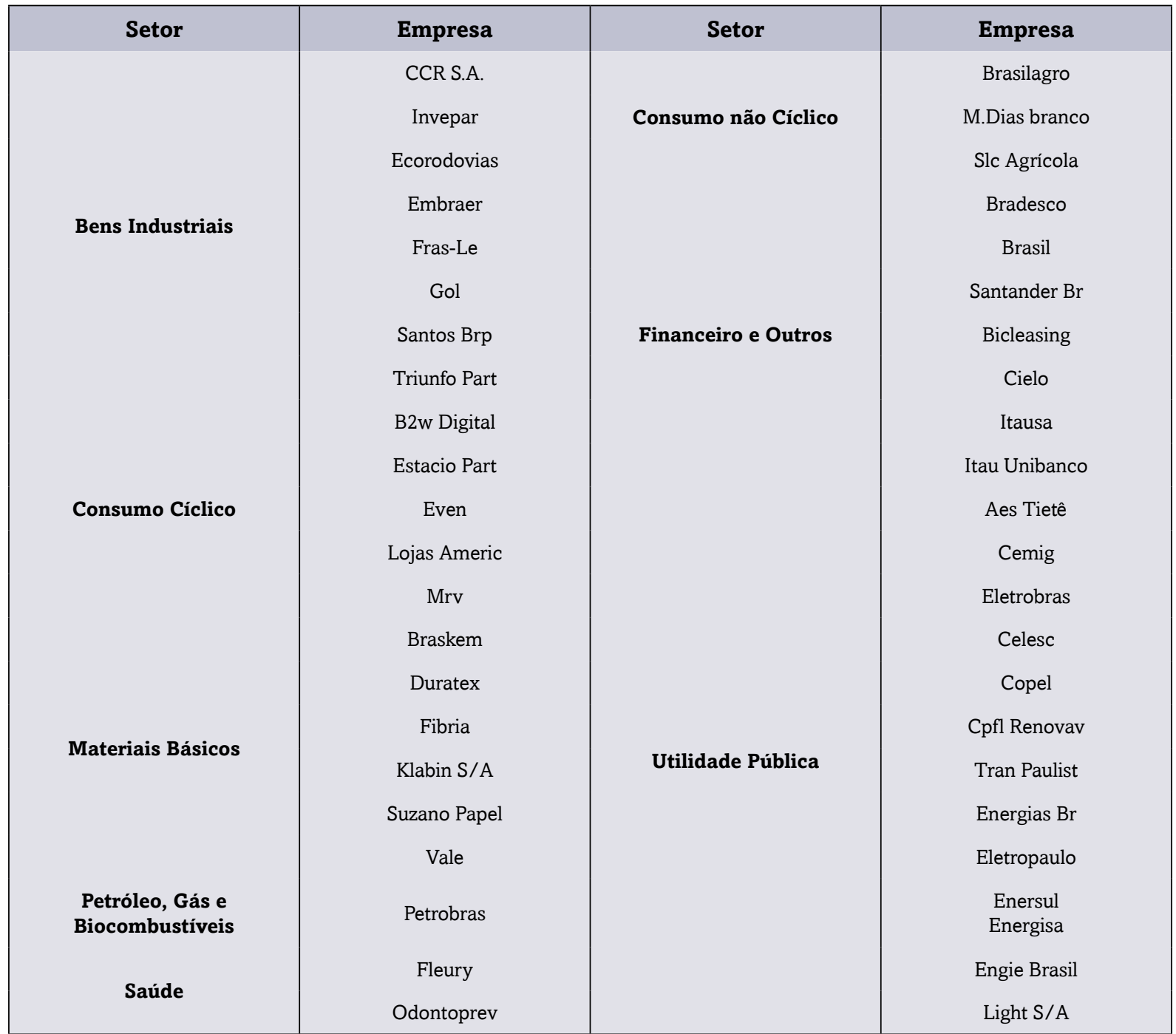

Fonte: elaborada pelos autores.

Os dados foram coletados por meio da análise de conteúdo dos relatórios de sustentabilidade. Esses documentos foram obtidos nos sites institucionais das empresas amostradas na Figura 1. Para a análise, foi atribuído o valor 1 (um) caso a empresa apresentasse algum programa ou ação voltado para determinado ODS e 0 (zero) quando não era identificada nenhuma ação em prol do respectivo ODS. Os 17 itens de verificação e as suas descrições são apresentados na Figura 2. 
Figura 2 - 17 Objetivos de Desenvolvimento Sustentável (ODS)

\begin{tabular}{|c|c|c|c|}
\hline $\begin{array}{l}\text { ERRADIGAGĀO } \\
\text { DAPOBREZAA }\end{array}$ & $\begin{array}{l}\text { FOME ZEROE } \\
\text { AGRICULTURA }\end{array}$ & $\begin{array}{l}\text { SAŌDEE } \\
\text { BEM-ESTAR }\end{array}$ & $\begin{array}{l}\text { EDUCACĀ̃ODE } \\
\text { QUALIDADE }\end{array}$ \\
\hline $\begin{array}{c}1 \text { - Acabar com a pobreza em } \\
\text { todas as suas formas, em todos } \\
\text { os lugares. }\end{array}$ & $\begin{array}{c}2 \text { - Acabar com a fome, alca- } \\
\text { nçar a segurança alimentar } \\
\text { e melhoria da nutrição e } \\
\text { promover a agricultura suste- } \\
\text { ntável. }\end{array}$ & $\begin{array}{c}3 \text { - Assegurar uma vida } \\
\text { saudável e promover o } \\
\text { bem-estar para todas e todos, } \\
\text { em todas as idades. }\end{array}$ & $\begin{array}{l}4 \text { - Assegurar a educação } \\
\text { inclusiva e equitativa e de } \\
\text { qualidade, e promover opor- } \\
\text { tunidades de aprendizagem } \\
\text { ao longo da vida para todas e } \\
\text { todos. }\end{array}$ \\
\hline 5 IGUALDADE & $\begin{array}{l}\text { (6) ATUAPOTAVEL } \\
\text { ESANEAMENTO }\end{array}$ & $\begin{array}{l}7 \text { ENEREIAAGESSIVII. } \\
\text { ELIMPA }\end{array}$ & $\begin{array}{l}\text { TRABALHO DECENTEE } \\
\text { GRESGIMENTO } \\
\text { EGONOMIGO }\end{array}$ \\
\hline $\begin{array}{c}5 \text { - Alcançar a igualdade de } \\
\text { gênero e empoderar todas as } \\
\text { mulheres e meninas. }\end{array}$ & $\begin{array}{c}6 \text { - Assegurar a disponibilidade } \\
\text { e gestão sustentável da água } \\
\text { e saneamento para todas e } \\
\text { todos. }\end{array}$ & $\begin{array}{l}7 \text { - Assegurar o acesso con- } \\
\text { fiável, sustentável, moderno } \\
\text { e a preço acessível à energia } \\
\text { para todas e todos. }\end{array}$ & $\begin{array}{l}8 \text { - Promover o crescimento } \\
\text { econômico sustentado, inclu- } \\
\text { sivo e sustentável, emprego } \\
\text { pleno e produtivo e trabalho } \\
\text { decente para todos. }\end{array}$ \\
\hline $\begin{array}{l}\text { G INDOSTRIA, INOVAGĀO } \\
\text { EINFRAESTRUTURA }\end{array}$ & $\begin{array}{l}\text { REDUCAODAS } \\
\text { DESIGUALDADES }\end{array}$ & 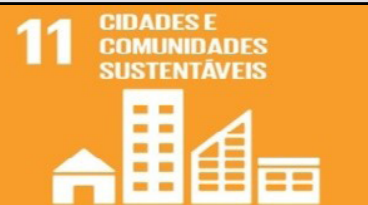 & $\begin{array}{l}\text { GONSUMOE } \\
\text { PRODUCÄO } \\
\text { RESPONSÄVEIS }\end{array}$ \\
\hline $\begin{array}{l}9 \text { - Construir infraestruturas re- } \\
\text { silientes, promover a industri- } \\
\text { alização inclusiva e sustentável } \\
\text { e fomentar a inovação. }\end{array}$ & $\begin{array}{l}10 \text { - Reduzir a desigualdade } \\
\text { dentro dos países e entre eles. }\end{array}$ & $\begin{array}{l}11 \text { - Tornar as cidades e os } \\
\text { assentamentos humanos } \\
\text { inclusivos, seguros, resilientes } \\
\text { e sustentáveis. }\end{array}$ & $\begin{array}{l}12 \text { - Assegurar padrões de } \\
\text { produção e de consumo sus- } \\
\text { tentáveis. }\end{array}$ \\
\hline $\begin{array}{l}13 \text { AGAOCONTRAA } \\
\text { MUDANGAGLOBAL } \\
\text { DOGLIMA }\end{array}$ & 14. VIDANA & t) VIDA & $\begin{array}{l}16 \text { PAZ, JUSTICAE } \\
\text { INSIIIUICOES } \\
\text { EFIGAZES }\end{array}$ \\
\hline $\begin{array}{l}13 \text { - Tomar medidas urgentes } \\
\text { para combater a mudança } \\
\text { climática e seus impactos. }\end{array}$ & $\begin{array}{c}14 \text { - Conservação e uso suste- } \\
\text { ntável dos oceanos, dos mares } \\
\text { e dos recursos marinhos para } \\
\text { o desenvolvimento suste- } \\
\text { ntável. }\end{array}$ & $\begin{array}{l}15 \text { - Proteger, recuperar e } \\
\text { promover o uso sustentável } \\
\text { dos ecossistemas terrestres, } \\
\text { gerir de forma sustentável as } \\
\text { florestas, combater a desert- } \\
\text { ificação, deter e reverter a } \\
\text { degradação da terra, e deter a } \\
\text { perda de biodiversidade. }\end{array}$ & $\begin{array}{l}16 \text { - Promover sociedades } \\
\text { pacíficas e inclusivas para o } \\
\text { desenvolvimento sustentável, } \\
\text { proporcionar o acesso à justiça } \\
\text { para todos e construir institu- } \\
\text { ições eficazes, responsáveis e } \\
\text { inclusivas em todos os níveis. }\end{array}$ \\
\hline
\end{tabular}

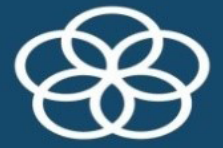

17 - Fortalecer os meios de implementação e revitalizar a parceria global para o desenvolvimento sustentável.

Fonte: ONUBR (2018) 


\subsection{Definição do Modelo}

Os 17 ODS nortearam a busca nos relatórios de sustentabilidade das 44 empresas que constituem a amostra. Após a coleta de dados, foi realizada a Análise Fatorial, no software STATA 12.0, para resumir o conjunto de 17 variáveis em um número menor. Conforme destacado por Mingoti (2005), o fatorial tem a finalidade de obter, por meio de variáveis diretamente observáveis, características e constructos que não são diretamente observáveis. Assim, os fatores descrevem as características marcantes dos dados de forma sintetizada.

De acordo com Hair, Black, Babin, Anderson e Tatham (2009), a análise fatorial deve ser aplicada quando há ao menos cinco vezes mais observações que o número de variáveis. Para verificar a adequabilidade dos dados ao modelo, foi realizado o teste de esfericidade Bartlett, que tem como hipótese nula que a matriz de correlações é estatisticamente igual à matriz identidade e como hipótese alternativa que ambas as matrizes são diferentes; para os dados estarem adequados, deve-se rejeitar a hipótese nula (Mingoti, 2005).

O Kayser Meyer Olkin (KMO) é um indicador que varia entre 1 e 0, e avalia se a análise fatorial está adequada, sendo que, quanto mais próximo de 1, melhor. De acordo com Hair, Anderson e Tatham (1987), valores acima de 0,5 são aceitáveis. O ajuste do modelo também pode ser avaliado pela comunalidade, que é a proporção de variabilidade de cada variável que é explicada pelos fatores, e os valores devem ser superiores a 0,5 (Hair et al., 2009).

Para selecionar os fatores, deve-se levar em consideração a capacidade de interpretá-los e o autovalor. Conforme o critério de Kaiser (1958), apenas fatores com autovalores acima de 1,0 devem ser levados em consideração (Hair et al., 2009). A segregação e interpretação dos fatores podem ser difíceis quando as cargas fatoriais são semelhantes e não desprezíveis, ou seja, superiores a 0,3 (Hair et al., 2009). Diante disso, pode-se aplicar a rotação dos fatores, pois tal procedimento não altera o resultado do KMO, do teste de Bartlett ou da variância obtida, apenas rearranja os fatores fazendo com que cada variável tenha carga fatorial alta em um único fator, facilitando, assim, a seleção e a interpretação dos fatores (Mingoti, 2005).

\section{ANÁLISE E DISCUSSÃO DOS RESULTADOS}

\subsection{Estatística descritiva dos dados}

Para analisar as características dos dados, foi utilizada a estatística descritiva. Conforme observado na Tabela 1, a maioria dos relatórios de sustentabilidade analisados seguem o padrão da GRI. Diante disso, alguns já trazem em seu sumário os ODS nos quais a empresa está envolvida. Esse resultado corrobora o estudo de Corrêa, Souza, Ribeiro e Ruiz (2013), pois demonstra que o aumento na adesão aos padrões GRI manteve-se, atingindo quase a totalidade das empresas amostradas.

Tabela 1 - Características das empresas amostradas

\begin{tabular}{c|c|c}
\hline \multicolumn{2}{c}{ Características das empresas amostradas } \\
\hline & Sim & Não \\
Índice de Sustentabilidade Empresarial & $70 \%$ & $30 \%$ \\
Adoção de padrões GRI & $95 \%$ & $5 \%$ \\
\hline
\end{tabular}

Fonte: dados da pesquisa.

Além de adotar o modelo de GRI, cerca de 70\% das empresas que declaram levar em consideração os 17 ODS estão no ISE. Esse resultado corrobora o estudo de Schio et al. (2019), que revelou que as empresas do ISE possuem maior envolvimento e divulgação das medidas para atingimento dos 17 ODS.

A Figura 3 demonstra o percentual de ações voltadas para cada ODS. Observa-se que os ODS nos quais as empresas apresentaram mais ações foram os identificados pelos números 3 (saúde e bem-estar) e 4 (educação de qualidade). As empresas amostradas possuem diversas ações voltadas para os trabalhadores, tais como plano de saúde, incentivo à educação, auxílio-alimentação, prevenção de acidentes e oficinas de lazer. As empresas também investem em capacitação tanto dos funcionários quanto da comunidade. Dentro das instituições, os trabalhadores possuem treinamentos, e algumas empresas oferecem auxílio para formação superior. Além disso, promovem projetos para capacitação de jovens das comunidades locais. 
Figura 3 - Percentual de açoes voltadas para cada ODS

Percentual de ações voltadas para cada ODS

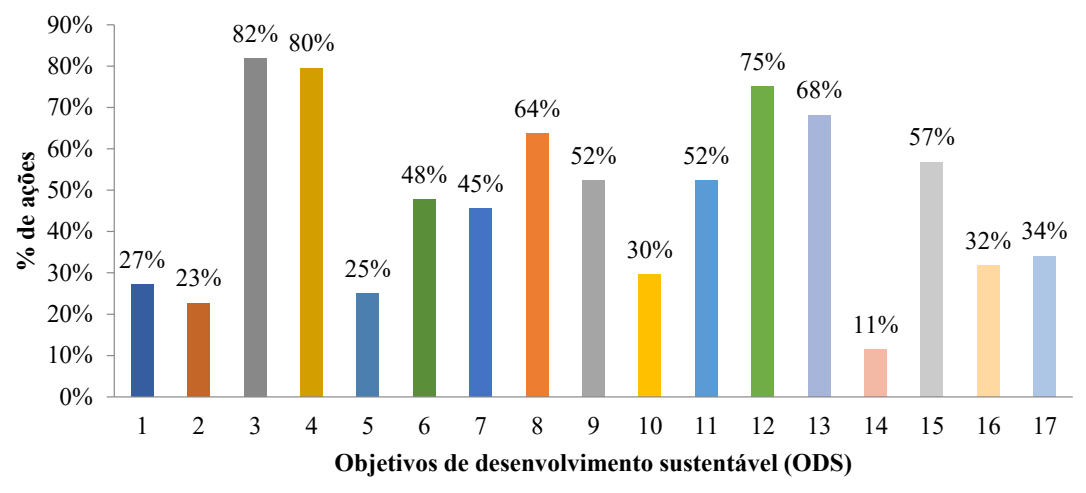

Fonte: dados da pesquisa.

Em contrapartida, os ODS que apresentaram menos ações voltadas para seu atingimento foram os de número 1 (erradicação da pobreza), 2 (fome zero e agricultura sustentável), 5 (igualdade de gênero) e 14 (vida na água). Assim, apesar de algumas empresas adotarem ações voltadas para estes ODS, é necessária uma maior atenção, dado o baixo número de medidas adotadas para atingir esses objetivos.

De forma geral, os resultados encontrados apontam que as empresas adotam medidas em relação aos ODS que estão mais voltados para sua atividade-fim. Conforme a Tabela 2, o setor de bens industriais e o de utilidade pública foram os que mais apresentaram ações em prol dos 17 ODS, 44,06\% do total de ações encontradas, dado que sua atividade impacta o ambiente, a sociedade e a economia.

As principais ações adotadas foram: investimento em energias renováveis; investimentos em tecnologias de produção e incentivos para desenvolvimento de novos processos; implantação de aproveitamento energético em comunidades; coleta seletiva e destinação correta dos resíduos de produção; reflorestamento de áreas degradadas; e parcerias com ONGs e associações a fim de promover o desenvolvimento sustentável. 
Tabela 2 - Ações adotadas por setor

\begin{tabular}{|c|c|c|c|c|c|c|c|}
\hline 17 ODS & $\begin{array}{c}\text { Bens } \\
\text { Industriais } \\
(\%)\end{array}$ & $\begin{array}{l}\text { Consumo } \\
\text { Cíclico (\%) }\end{array}$ & $\begin{array}{c}\text { Consumo } \\
\text { não Cíclico } \\
(\%)\end{array}$ & $\begin{array}{c}\text { Financeiro } \\
\text { e Outros } \\
(\%)\end{array}$ & $\begin{array}{c}\text { Materiais } \\
\text { Básicos } \\
\text { (\%) }\end{array}$ & Saúde (\%) & $\begin{array}{c}\text { Utilidade } \\
\text { Pública } \\
\text { (\%) }\end{array}$ \\
\hline 1- Pobreza & 1.85 & 0.00 & 4.17 & 3.92 & 1.49 & 11.11 & 4.9 \\
\hline 2- Fome Zero & 1.85 & 0.00 & 0.00 & 3.92 & 2.99 & 5.56 & 3.92 \\
\hline 3-Saúde & 9.26 & 10.53 & 12.5 & 13.73 & 7.46 & 11.11 & 9.8 \\
\hline 4- Educação & 9.26 & 13.16 & 12.5 & 11.76 & 7.46 & 11.11 & 8.82 \\
\hline 5- Gênero & 5.56 & 5.26 & 0.00 & 3.92 & 1.49 & 0 & 2.94 \\
\hline 6- Saneamento & 5.56 & 2.63 & 0.00 & 7.84 & 7.46 & 11.11 & 5.88 \\
\hline 7- Energia & 5.56 & 2.63 & 4.17 & 7.84 & 7.46 & 5.56 & 4.9 \\
\hline 8- Crescimento & 7.41 & 13.16 & 8.33 & 5.88 & 7.46 & 5.56 & 7.84 \\
\hline Econômico & & & & & & & \\
\hline 9- Inovação & 7.41 & 5.26 & 4.17 & 5.88 & 8.96 & 5.56 & 5.88 \\
\hline 10- Desigualdade & 1.85 & 0.00 & 4.17 & 3.92 & 7.46 & 0.00 & 3.92 \\
\hline 11- Cidades & 7.41 & 7.89 & 8.33 & 1.96 & 7.46 & 5.56 & 6.86 \\
\hline 12- Consumo & 11.11 & 13.16 & 8.33 & 7.84 & 7.46 & 11.11 & 8.82 \\
\hline 13- Clima & 9.26 & 10.53 & 8.33 & 9.8 & 7.46 & 11.11 & 6.86 \\
\hline 14- Vida Na Água & 1.85 & 0.00 & 4.17 & 0.00 & 1.49 & 0.00 & 1.96 \\
\hline 15- Vida Terrestre & 7.41 & 5.26 & 8.33 & 5.88 & 5.97 & 0.00 & 9.8 \\
\hline 16- Justiça & 3.7 & 5.26 & 8.33 & 1.96 & 5.97 & 0.00 & 2.94 \\
\hline 17- Parcerias & 3.7 & 5.26 & 4.17 & 3.92 & 4.48 & 5.56 & 3.92 \\
\hline $\begin{array}{l}\text { Total de ações } \\
\text { por Setor }\end{array}$ & 108 & 76 & 48 & 102 & 134 & 36 & 204 \\
\hline$\%$ & 15.25 & 10.73 & 6.78 & 14.41 & 18.93 & 5.08 & 28.81 \\
\hline
\end{tabular}

Fonte: dados da pesquisa.

Observa-se que os ODS que receberam mais atenção, em todos os segmentos analisados, foram os de número 3 (Saúde) e 4 (Educação), uma vez que as empresas analisadas, em sua maioria, demonstraram disponibilizar planos de saúde para os seus colaboradores e informaram também investimentos em formação e capacitação de seus funcionários.

O ODS de número 12 (Consumo) destacou-se, pois as empresas analisadas relataram que buscaram implantar medidas para redução de desperdícios, diminuição na geração de resíduos por meio da reciclagem e redução ou prevenção das perdas. O ODS de número 13 (Clima) também merece destaque, visto que as companhias evidenciaram a operacionalização de medidas para minimização dos impactos da atividade-fim nas mudanças climáticas, como programas para redução de Gases do Efeito Estufa (GEE).

As empresas que compõem a amostra apresentaram condutas que vão ao encontro dos 17 ODS, porém essas ações são mais restritas ao âmbito interno da organização. Ainda são pouco evidentes, por parte das empresas, práticas que possuem maior impacto socioeconômico, como erradicação da pobreza e da fome. Salienta-se que, de acordo com o Instituto de Brasileiro de Geografia e Estatística (IBGE), em 2018, cerca de 25,0\% dos brasileiros viviam em situação de pobreza, dificultando o acesso às necessidades básicas, como alimentação, educação, emprego, água potável e saneamento básico (Oliveira, 2012; Ammann, 2016).

Diante disso, juntamente às políticas públicas, as empresas devem buscar ampliar as ações voltadas para o âmbito externo, gerando, assim, crescimento econômico e melhores condições de vida para a sociedade. Dessa forma, carece de mais atenção os ODS pobreza, fome zero, saneamento e redução das desigualdades para contribuir com o desenvolvimento mais sustentável da sociedade. 


\subsection{Modelo Econométrico}

A análise fatorial foi gerada para 17 variáveis e 88 observações, assim a quantidade de dados é cinco vezes maior, conforme indicado por Hair et al. (2009). A comunalidade para todas as variáveis foi superior a 0,5, indicando que estão adequadas ao modelo, conforme demonstrado na Tabela 3.

Tabela 3 - Análise Fatorial

\begin{tabular}{|c|c|c|c|c|c|}
\hline \multirow{2}{*}{ Variáveis - ODS } & Fator 1 & Fator 2 & Fator 3 & Fator 4 & \multirow{2}{*}{ Comunalidade } \\
\hline & Econômico & Ambiental & Social & Preservação & \\
\hline 1- Erradicação da pobreza & 0.142 & 0.044 & 0.516 & 0.143 & 0.625 \\
\hline 2- Fome zero e agricultura sustentável & 0.3 & 0.106 & 0.004 & 0.213 & 0.829 \\
\hline 3- Saúde e bem-estar & 0.032 & 0.462 & 0.591 & 0.071 & 0.603 \\
\hline 4- Educação de qualidade & 0.014 & -0.064 & 0.864 & 0.142 & 0.777 \\
\hline 5- Igualdade de gênero & 0.747 & 0.062 & -0.019 & 0.057 & 0.628 \\
\hline 6- Água potável e saneamento & 0.302 & 0.805 & -0.067 & 0.207 & 0.83 \\
\hline 7- Energia acessível e limpa & 0.155 & 0.814 & 0.062 & 0.026 & 0.742 \\
\hline $\begin{array}{l}\text { 8- Trabalho decente e crescimento } \\
\text { econômico }\end{array}$ & -0.006 & 0.116 & 0.332 & 0.07 & 0.79 \\
\hline 9- Indústria, inovação e infraestrutura & 0.769 & 0.28 & 0.055 & -0.131 & 0.738 \\
\hline 10 - Redução das desigualdades & 0.607 & 0.074 & 0.176 & 0.231 & 0.52 \\
\hline 11 - Cidades e comunidades sustentáveis & 0.715 & 0.129 & 0.191 & 0.383 & 0.711 \\
\hline 12 - Consumo e produção responsáveis & 0.299 & 0.18 & 0.686 & -0.073 & 0.674 \\
\hline 13- Ação contra a mudança global de clima & 0.011 & 0.702 & 0.401 & -0.003 & 0.742 \\
\hline 14 - Vida na água & 0.06 & 0.065 & 0.078 & 0.903 & 0.867 \\
\hline 15 - Vida terrestre & 0.375 & 0.416 & -0.034 & 0.477 & 0.675 \\
\hline 16 - Paz, justiça e instituições eficazes & 0.176 & 0.073 & 0.068 & 0.04 & 0.722 \\
\hline 17 - Parcerias e meios de implementação & 0.397 & 0.095 & 0.179 & 0.574 & 0.696 \\
\hline Variância Explicada & $15,75 \%$ & $13,97 \%$ & $13,10 \%$ & $10,24 \%$ & \\
\hline $\begin{array}{l}\text { Variância Acumulada } \\
\text { KMO }=0,6784 \\
\text { Teste de Bartlett: p-valor: } 0.0000\end{array}$ & $15,75 \%$ & $29,72 \%$ & $42,82 \%$ & $53,05 \%$ & \\
\hline
\end{tabular}

Fonte: Dados da pesquisa.

O KMO apresentou um valor de 0,6784, sendo considerado aceitável (Hair et al., 1987). O teste de esfericidade de Bartlett indica que a matriz de correlações é diferente da matriz identidade, logo os dados estão adequados (Mingoti, 2005). Para facilitar a interpretação e seleção dos fatores, foi utilizada a técnica de rotação varimax. Assim, foram gerados seis fatores, destes foram considerados para análise aqueles com autovalor maior que 1 e com o maior número de cargas fatoriais superiores a 0,3 agrupadas.

Portanto, a análise fatorial agrupou os ODS mais representativos em quatro fatores, denominados de Econômico, Social, Ambiental e Preservação. A segregação dos fatores obtidos contribui com o estudo de Elkington (1997), pois os 17 ODS, que são variáveis diretamente observáveis, formam fatores, não diretamente observáveis, relacionados aos pilares do desenvolvimento sustentável, que são os aspectos ambientais, sociais e econômicos.

Dentro do fator Econômico, as ações identificadas, nos relatórios de sustentabilidade, que mais se destacaram foram as voltadas para o ODS numero 9 "Indústrias, Inovação e Infraestrutura”. As principais medidas adotadas dentro desse ODS foram destinadas para investimentos em tecnologias de produção e incentivos para desenvolvimento de novos processos. Para Verba e Igor'Nikolaevich (2015), as organizações devem utilizar o desenvolvimento tecnológico para otimizar as tarefas e preservar os recursos humanos e naturais, ou seja, devem estar alinhadas com as questões relacionadas à sustentabilidade. 
Ainda, dentro do fator Econômico, as ações voltadas para o ODS n. ${ }^{\circ} 11$ "Cidades e Comunidades Sustentáveis" concentram-se na implantação de aproveitamento energético em comunidades, melhorias em escolas e postos de saúde. Para "Redução das desigualdades", ODS n. ${ }^{\circ}$ 10, são adotadas medidas como implementação de fundações para capacitação e qualificação profissional, associações para melhorar a agricultura familiar, geração de empregos locais e incentivos à educação.

Já em relação ao ODS n. ${ }^{\circ} 5$ "Igualdade de Gênero", as principais medidas estabelecidas foram voltadas para equilibrar o número de homens e mulheres nos cargos de gestão, basear a remuneração em critérios meritocráticos e oferecer licença-maternidade estendida. De acordo com o relatório UN WOMEN (2015), as desigualdades prejudicam o desenvolvimento, pois desperdiçam talentos e dificultam o dinamismo econômico e social. Ainda de acordo com esse relatório, as mulheres são prejudicadas, pois, além de exercerem as atividades profissionais, são responsáveis por grande parte dos cuidados domésticos.

$\mathrm{O}$ fator Ambiental apresentou os ODS relacionados ao meio ambiente. As medidas adotadas para contribuir com o ODS n. ${ }^{\circ} 7$ "Energia Acessível e Limpa" foram investimentos em energias renováveis, como a solar, e mudanças de estruturas físicas para melhor aproveitamento das energias renováveis. Já em relação à ação de "Combate às Alterações Climáticas”, ODS n. ${ }^{\circ} 13$, as medidas adotadas foram a redução na emissão de $\mathrm{CO}^{2}$ com adequação de frotas e otimização de rotas.

As principais ações relacionadas aos aspectos ambientais encontradas nos relatórios de sustentabilidade foram voltadas para a mitigação do efeito estufa. Diante disso, foram localizadas ações para redução do consumo de combustíveis fósseis. Tal preocupação pode estar relacionada aos impactos econômicos gerados pelas alterações climáticas, como furação, enchetes e seca (Stern \& Stern, 2007). Em relação ao ODS n. ${ }^{\circ} 6$ “Água potável e saneamento”, as principais medidas adotadas foram criação de poços artesianos, sistemas de captação de água, tratamento e descarte adequado aos resíduos, captação da água da chuva e implementação de sistemas de tratamento e reutilização da água.

A colaboração das empresas com a preservação dos recursos hídricos, bem como com a melhora do saneamento básico, é importante, pois, de acordo com o IBGE (2018), cerca de 35\% dos brasileiros não possuem acesso à rede de esgoto. Tal fato gera diversos problemas de saúde pública, como proliferação de pragas urbanas (ratos, baratas, Aedes aegypti, etc), desenvolvimento de doenças como hepatite, leptospirose, disenteria, mortalidade infantil, diminuindo, assim, as oportunidades socioeconômicas dessa população vunerável (ONU, 2017).

O terceiro fator agrupou os ODS Sociais. Dentro das ações em prol da Educação de Qualidade, ODS n. ${ }^{\circ} 4$, as empresas realizam cursos de formação e capacitação para todos os níveis hierárquicos e ofertam auxílio financeiro para custear cursos de graduação e pós-graduação, sendo que tal resultado corrobora o estudo de Castro (2018). As principais medidas adotadas para contribuir com o ODS n. 3 "Saúde e Bem-estar" foram atendimento psicossocial e médico aos colaboradoes e dependentes, plano de saúde, seguro de vida e incentivo à prática de esporte.

De acordo com o relatório International Labour Organization, publicado em 1986, pela Organização Mundial de Saúde (OMS) e pela Organização Internacional do Trabalho (OIT), o desenvolvimento econômico não está atrelado apenas a fatores relacionados à produção, mas também a condições de vida, trabalho, saúde e bem-estar dos trabalhadores e de seus familiares. Diante disso, as empresas estão buscando cada vez mais investir e divulgar dados a respeito dos colaboradores. Consumo e Produção Responsável, ODS n. ${ }^{\circ}$ 12, também compõe o fator Social, e as principais ações adotadas pelas empresas foram coleta seletiva, destinação correta e redução dos resíduos de produção.

O quarto fator denominado de Preservação também está relacionado aos aspectos ambientais. As principais ações voltadas para o ODS n. 14 "Vida Debaixo D’Água" foram tratamento de rejeitos antes de serem lançados na água, monitoramento da fauna aquática e controle do uso de agrotóxicos, e tais resultados corroboram o estudo de Singh et al. (2018). Para contribuição com o ODS n. ${ }^{\circ} 15$ "Vida Terrestre", as empresas adotaram medidas como implementação de travessia de animais, criação de taludes para reduzir a erosão do solo, resgate e monitoramento de animais silvestres, reflorestamento, rotação de cultura e criação de áreas de proteção ambiental.

As "Parcerias e Meios de Implementação", ODS n. ${ }^{\circ}$ 17, estão relacionadas ao apoio das companhias a ONGs e a associações, a fim de promover o desenvolvimento sustentável. Diversas empresas possuem ou mantêm fundações e fazem parcerias para melhorar suas atividades, bem como para interagir e desenvolver a comunidade local em aspectos ambientais, econômicos e sociais.

O fator Econômico possui a maior capacidade de explicação, pois são os ODS que, de forma direta ou indireta, impactam a economia. Quanto menor a carga fatorial da variável, dentro de determinado fator, menos ações voltadas para aquele ODS são identificadas. Porém, a ausência de atitudes em prol de algum ODS pode ser explicada pelo fato de a atividade-fim da empresa não ser relacionada com o respectivo objetivo de desenvolvimento sustentável. Por exemplo, empresas do setor financeiro, dificilmente, realizaram ações concernentes à vida na água, que consiste em proteção da fauna e flora dos mares.

\section{CONSIDERAÇÕES FINAIS}

A pesquisa teve o objetivo de identificar nos relatórios de sustentabilidade das empresas da B3, publicados nos anos de 2017 e 2018, ações voltadas para a promoção dos 17 ODS. A divulgação dos ODS é apresentada de diferentes formas pelas empresas, algumas destas destacam essas metas ao longo do texto; outras, no sumário da GRI; e algumas apenas citavam que levavam em consideração tal aspecto. Sendo assim, por meio da análise fatorial, chegou-se a 4 (quatro) fatores, que são: Econômicos, Sociais, Ambientais e de Preservação. Dentro destes fatores, há diversos ODS representativos, os quais foram utilizados para análise. 
Diante disso, a pesquisa concluiu que as empresas, de fato, adotam medidas sustentáveis, seja em suas operações, seja com o intuito de contribuir com a comunidade ou com o meio ambiente. No entanto, observou-se que muitas medidas são adotadas no âmbito interno para refletir no externo. Por exemplo, no fator Ambiental, adotam-se diversas medidas como tratamento de resíduos, controle do consumo de água, energia e redução da emissão dos gases do efeito estufa, porém há poucas ações voltadas diretamente para o âmbito externo, como o replantio de árvores ou cuidado com os mares.

Dessa forma, a pesquisa permite destacar que alguns ODS precisam de mais atenção, tais como Fome Zero e Igualdade de Gênero. Acerca deste último, apesar de as empresas terem políticas de salários meritocráticas, foram observadas poucas medidas para, concretamente, reduzir as desigualdades de homens e mulheres. Dentro desta perspectiva, verificou-se que o número de funcionários homens em, praticamente, todas as empresas é maior que o de mulheres.

A pesquisa apresenta algumas limitações, entre elas a temporal, visto que foram analisados apenas os anos inicias da adequação das empresas aos ODS. Sugere-se acompanhar a evolução da implementação de ações em prol dos ODS ao longo do tempo. Outra limitação a ser destacada foi o número de empresas utilizadas, tendo em vista que, por se tratar de uma divulgação voluntária, a quantidade fica prejudicada. Além disso, de acordo com a Teoria da Divulgação Voluntária, as empresas tendem a relatar apenas pontos positivos nos relatórios anuais, o que dificulta a análise de falhas e pontos que precisam de mais atenção em relação ao atingimento dos objetivos e metas de desenvolvimento sustentável.

A principal contribuição do trabalho é analisar, de forma crítica, o que as companhias têm feito para serem mais sustentáveis, seja no âmbito econômico, social ou ambiental, e mostrar que, realmente, a sustentabilidade é um fator que preocupa as empresas da B3. No entanto, ainda há necessidade de mais atenção e esforço em prol de realizarem ações para contribuírem com a Agenda 2030. A pesquisa contribui ainda com a discussão da Teoria da Divulgação Voluntária, de Dye (2001) bem como com a pesquisa de Coelho et al. (2013), pois analisa de forma criteriosa os relatórios de sustentabilidade e conclui que as empresas não costumam divulgar dados desfavoráveis. Assim, reforça as pequisas dos autores demonstrando que os relatórios evidenciam os projetos e ações favoráveis à entidade e deixam de lado as dificuldades, falhas ou omissões.

Outrossim, a pesquisa contribui com os estudos de Costa e Marion (2007), Ribeiro et al. (2011) e Calixto (2013), uma vez que também foram encontradas dificuldades de analisar os relatórios de sustentabilidade, devido à falta de uniformidade na estrutura e nas informações reportadas. A falta de obrigatoriedade gera relatórios pouco comparáveis, pois cada entidade tem uma grande discricionariedade para reportar a informação.

Com sugestão de pesquisas futuras, podem-se fazer os seguintes estudos: analisar todos os relatórios de sustentabilidade, e não apenas os das empresas que declaram levar em consideração os 17 ODS, a fim de verificar se todas as empresas que publicam relatórios têm realizado ações em prol do desenvolvimento sustentável e quais são essas medidas. Além disso, pode-se criar um índice, a partir desses resultados, e verificar o impacto de variáveis de desempenho nas práticas sustentáveis.

\section{REFERÊNCIAS}

Almeida, F. (2009). O bom negócio da sustentabilidade. Nova Fronteira.

Ammann, S. B. (2016). Expresões da pobreza no Brasil: Análise a partir das desigualdades regionais. Cortez Editora.

Andrade, J. A. S. (2017). Avaliação e acompanhamento no Nivel Global da implementação da Agenda 2030 para o Desenvolvimento Sustentável (Dissertação de mestrado). Universidade Federal de Ouro Preto - UFOP, Ouro Preto, MG.

Brasil, Bolsa, Balcão [B3]. (2018). Sustentabilidade B3. Recuperado de http://www.b3.com.br/pt_br/b3/sustentabilidade/nas-empresas/relate-ou-explique/.

Bassetto, L. I. (2010) A incorporação da responsabilidade social e sustentabilidade: um estudo baseado no relatório de gestão 2005 da companhia paranaense de energia-COPEL. Gestão \& Produção, 17(3), pp. 639-651. DOI :https://doi.org/10.1590/S0104$530 \times 2010000300016$

Bellen, H. M. (2005). Indicadores de sustentabilidade: uma análise comparativa. São Paulo: FGV Editora.

Bossel, H. (1999). Indicators for sustainable development: theory, method, applications (p. 138). Winnipeg: International Institute for Sustainable Development.

Brown, H. S., Jong, M. \& Levy, D. L. (2009) Building institutions based on information disclosure: lessons from GRI's sustainability reporting. Journal of Cleaner Production, 17(6), pp. 571-580. DOI: https://doi.org/10.1016/j.jclepro.2008.12.009.

Calixto, L. A. (2013). divulgação de relatórios de sustentabilidade na América Latina: um estudo comparativo. Revista de Administração, 48(4), pp. 828-842. DOI: https://doi.org/10.5700/rausp1124.

Campos, L. M. S., Sehnem, S., Oliveira, M. D. A. S., Rossetto, A. M., Coelho, A. L. D. A. L., \& Dalfovo, M. S. Relatório de sustentabilidade: perfil das organizações brasileiras e estrangeiras segundo o padrão da Global Reporting Iniciative. Gestão \& Produção, 20(4), pp. 913-926, 2013. DOI: https://doi.org/10.1590/S0104-530X2013005000013.

Castro, C. M. F. (2018). Agenda 2030 para o desenvolvimento sustentável: uma leitura de política pública na clave da biblioteca escolar. Revista Digital de Biblioteconomia e Ciência da Informação, 16(3), 355-372. DOI: https://doi.org/10.20396/rdbci.v16i3.8650931.

Clarkson, P. M., Li, Y., Richardson, G. D. \& Vasvari, F. P. (2008). Revisiting the relation between environmental performance and environmental disclosure: An empirical analysis. Accounting, Organizations and Society, 33(4-5), 303-32. DOI: https://doi.org/10.1016/j. aos.2007.05.003. 
Coelho, F. Q., Ott, E., Pires, C. B. \& Alves, T. W. (2013). Uma Análise dos Diferenciadores na Divulgação de Informações Voluntárias sobre o Meio Ambiente. Contabilidade Vista \& Revista, 24(1), 112-130.

Conceição, S. H., Dourado, G. B. \& Silva, S. F. (2012). Global Reporting Initiative (GRI) - Um estudo exploratório da prática de evidenciação em sustentabilidade empresarial na América Latina. Revista Gestão, Finanças e Contabilidade, 2 (3),17-38, 2012. DOI: http:// dx.doi.org/10.18028/rgfc.v2i3.68.

Corrêa, R., Souza, M. T. S. D., Ribeiro, H. C. M. \& Ruiz, M. S. (2013). Evolução dos níveis de aplicação de relatórios de sustentabilidade (GRI) de empresas do ISE/Bovespa. Sociedade, Contabilidade e Gestão, 7(2). . DOI: https://doi.org/10.21446/scg_ufrj.v7i2.13268.

Costa, R. S. D. \& Marion, J. C. A. (2007). uniformidade na evidenciação das informações ambientais. Revista Contabilidade \& Finanças, 18(43), pp.20-33. DOI: https://doi.org/10.1590/S1519-70772007000100003.

Dye, R. A. (2001). An evaluation of "essays on disclosure" and the disclosure literature in accounting. Journal of Accounting and Economics, 32(1-3), 181-235. DOI: https://doi.org/10.1016/S0165-4101(01)00024-6.

Elkington, J. (1997). Cannibals with forks: the triple bottom line of 21st century business. New Society: Stony Creek.

Garcia, D. S. S. (2016). Dimensão econômica da sustentabilidade: uma análise com base na economia verde e a teoria do decrescimento. Veredas do Direito: Direito Ambiental e Desenvolvimento Sustentável, 13(25), 133-153. DOI: http://dx.doi.org/10.18623/rvd. v13i25.487.

Gonçalves, O. \& Ott, E. (2002) A evidenciação nas companhias brasileiras de capital aberto. In: Anais do Encontro Nacional da Anpad (Enanpad). Salvador, BA, Brasil.

Hair, J. F., Black, W. C., Babin, B. J., Anderson, R. E., \& Tatham, R. L. (2009). Análise multivariada de dados. Bookman Editora.

Hair, J. F., Anderson, R., Tatham, R. \& Black, W. (1987). Multivariate Data Analysis with Readings. Macmillan. New Work.

Halle, M. \& Wolfe, R. (2016). Follow-up and Review for the 2030 Agenda: Bringing coherence to the work of the HLPF. International Institute for Sustainable Development.

Instituto Brasileiro de Geografia e Estatística (IBGE). (2015). Pesquisa Nacional por Amostra de Domicilios, PNAD. Recuperado de: https://biblioteca.ibge.gov.br/visualizacao/livros/liv98887.pdf.

Instituto Brasileiro de Geografia e Estatística (IBGE). (2018). Pesquisa Nacional por Amostra de Domicílios, PNAD. Recuperado de: https://biblioteca.ibge.gov.br/visualizacao/livros/liv101654_informativo.pdf.

Instituto Brasileiro de Geografia e Estatística (IBGE). (2019). Síntese de Indicadores Sociais: Uma Análise das Condições de Vida da População Brasileira. IBGE. Recuperado de: https://biblioteca.ibge.gov.br/visualizacao/livros/liv101678.pdf.

International Labour Office (1986). Psychosocial factors at work: Recognition and control: report of the Joint ILO/WHO Committee on Occupational Health, ninth session, Geneva, 18-24. Recuperado de: http://www.ilo.org/public/libdoc/ilo/1986/86B09_301_ engl.pdf.

Iudícibus, S. (2010) Teoria da Contabilidade. 10 ed. São Paulo: Atlas.

Jones, P., Wynn, M., Hillier, D. \& Comfort, D. (2017). The sustainable development goals and information and communication technologies. Indonesian Journal of Sustainability Accounting and Management, 1(1), 1-15. DOI: https://doi.org/10.28992/ijsam.v1i1.22.

Kaiser, H. F. (1958). The varimax criterion for analytic rotation in factor analysis. Psychometrika, 23(3), $187-200$. DOI: https://doi.org/10.1007/BF02289233.

Lago, A. A. C. (2007). Estocolmo, Rio, Joanesburgo: o Brasil e a três conferências ambientais das Nações Unidas. Brasília: Thesaurus Editora.

Leite Filho, G. A. L., Prates, L. A. \& Guimarães, T. N. (2009). Análise dos níveis de evidenciação dos relatórios de sustentabilidade das empresas brasileiras A+ do Global Reporting Initiative (GRI) no ano de 2007. Revista Contabilidade e Organizações, 3 (7), 43-59.

Martins, G. A. \& Theóphilo, C. R. (2009). Metodologia da investigação cientifica para ciências sociais aplicadas. São Paulo, SP: Atlas.

Meadows, D. H., Meadows, D. L., Randers, J. \& Behrens, W. W. (1972). The limits to growth. New York, 102, 27.

Mingoti, S. A. (2005). Análise de dados através de métodos de estatística multivariada: uma abordagem aplicada. Editora UFMG

Oliveira, N. C. (2012) Desenvolvimento, sustentabilidade e relações internacionais: uma análise dos indicadores de desenvolvimento sustentável e sua aplicação ao caso brasileiro (Dissertação de Mestrado). Universidade Federal do Rio de Janeiro UFRJ, Rio de Janeiro, $\mathrm{RJ}$, Brasil.

Oliveira, S. (2012). Olhar a pobreza em Angola: causas, consequências e estratégias para a sua erradicação. Ciências Sociais Unisinos, 48(1), 29-40.

Organização Das Nações Unidas Brasil (ONU/BR) (2015). Transformando Nosso Mundo: A Agenda 2030 para o Desenvolvimento Sustentável. Recuperado de: https://nacoesunidas.org/pos2015/agenda2030/.

Organização das Nações Unidas Brasil. (ONUBR). (2017). ONU: 4,5 bilhões de pessoas não dispõem de saneamento seguro no mundo. Recuperado de: https://nacoesunidas.org/onu-45-bilhoes-de-pessoas-nao-dispoem-de-saneamento-seguro-no-mundo/>.

Pronk, J. \& ul Haq, M. (1992). Sustainable development: from concept to action. Ministry of Development Cooperation.).

PRICEWATERHOUSECOOPERS (PWC) (2017). Os desafios das empresas portuguesas na priorização dos ODS e no relato não-financeiro. Recuperado de: https://www.pwc.pt/pt/sustentabilidade/ods/pwc-report-ods.pdf.

Reverte, C. (2009). Determinants of corporate social responsibility disclosure ratings by Spanish listed firms. Journal of Business Ethics, 88(2), 351-366. DOI:10.1007/s10551-008-9968-9. 
Ribeiro, A. M., Bellen, H. M. V. \& Carvalho, L. N. G. D. (2011). Regulamentar faz diferença? O caso da evidenciação ambiental. Revista Contabilidade \& Finanças, 22(56), pp.137-154. . DOI: https://doi.org/10.1590/S1519-70772011000200002.

Romeiro, A. R. (2012). Desenvolvimento sustentável: uma perspectiva econômico- ecológica. Estudos Avançados, 26(74), pp. 6592. DOI: https://doi.org/10.1590/S0103-40142012000100006.

Rover, S., Tomazzia, E. C., Murcia, F. D. R., \& Borba, J. A. (2012). Explicações para a divulgação voluntária ambiental no Brasil utilizando a análise de regressão em painel. Revista de Administração, 47(2), 217-230. DOI: https://doi.org/10.1590/S008021072012000200005

Schio, N. D. S., Mazzioni, S., Moura, G. D., \& Dal Magro, C. B. (2019). Objetivos de Desenvolvimento Sustentável e as Empresas Participantes do Mercado Acionário Brasileiro. Anais do Congresso USP Controladoria e Contabilidade, São Paulo, SP, Brasil, 19.

Singh, G. G., Cisneros-Montemayor, A. M., Swartz, W., Cheung, W., Guy, J. A., Kenny, T. A., \& Sumaila, R. (2018). A rapid assessment of co-benefits and trade-offs among Sustainable Development Goals. Marine Policy, 93, 223-231. DOI: https://doi.org/10.1016/j. marpol.2017.05.030.

Stern, N. \& Stern, N. H. (2007). The economics of climate change: the Stern review. Cambridge University Press.

Verba, Y. S. \& Igor'Nikolaevich, I. (2015). Sustainable Development and Project Management; Objectives and Integration Results. Economic and Social Changes: Facts, 5(41), 135-146. DOI: https://doi.org/10.15838/esc/2015.5.41.9.

Verrecchia, R. E. (2001). Essays on disclosure. Journal of Accounting and Economics, 32(1-3), 97-180. DOI: https://doi.org/10.1016/ S0165-4101(01)00025-8.

World Commission on Environment and Development (WCED). (1987). Our common future. Oxford University Press.

Women, U. N. (2015). Progress of the world's women 2015-2016: Transforming economies, realizing rights. Recuperado de https:// www.unwomen.org/en/digital-library/publications/2015/4/progress-of-the-worlds-women-2015.

Yamamoto, M. M. \& Salottti, B. M. (2006). Informação contábil: estudos sobre a sua divulgação no mercado de capitais. São Paulo: Atlas. 